\title{
Net örtü sistemi altında muz yetiştirme olanakları
}

\section{Growing possibilities of banana in net covering system}

\author{
Lokman ALTINKAYA®, Hamide GÜBBÜK(i)
}

Akdeniz Üniversitesi, Ziraat Fakültesi, Bahçe Bitkileri Bölümü, Kampüs, 07058, Antalya

Sorumlu yazar (Corresponding author): H. Gübbük, e-posta (e-mail): gubbuk@akdeniz.edu.tr Yazar(lar) e-posta (Author e-mail): lokmanaltinkaya@ hotmail.com

\section{MAKALE BİLGİSİ}

Alınış tarihi 30 Ağustos 2019

Düzeltilme tarihi 11 Haziran 2020

Kabul tarihi 01 Temmuz 2020

\section{Anahtar Kelimeler:}

Muz

Örtü materyali

Yetiştirme sistemi

Verim

Kalite

\section{ÖZ}

Subtropik koşullarda muz yetiştiriciliğinde, üretim maliyetini arttıran en önemli unsurlardan birisi sera kurulum maliyetidir. Bununla birlikte, arazi yapısının engebeli olmasından dolayı sera kurulumunun mümkün olamayacağı araziler de bulunmaktadır. Bu nedenle engebeli arazilerde modern seraların kurulumu üretim maliyetini arttırmaktadır. Ayrıca sera örtï materyali olarak plastik kullanımı yağmur sularından yararlanılmasını engellemektedir. $\mathrm{Bu}$ nedenle planlanan bu çalışmada sera kurulumuna uygun olmayan arazilerde net örtü sistemi altında yapılan muz yetiştiriciliğinin açıkta yetiştiricilik ile kıyaslanması amaçlanmıştır. Araștırma, 2015-2016 yılları arasında Antalya'nın Gazipaşa ilçesinin Yakacık mevkiinde yürütülmüştür. "Dwarf Cavendish" çeşidinin kullanıldığı çalışmada, konstrüksiyon olarak galvenizli demir ve örtü sistemi olarak ise beyaz renkli böcek tülü (UV stabilizasyonu sağlayan, \%8-12 gölgelemeye sahip ve doluya dayanıklı, 25 mesh 10X8 gözenek genişliğinde) kullanılmıştır. Araştırmada, morfolojik özellikler (gövde çevresi, gövde yüksekliği, yaprak sayısı, hevenk sapı çevresi), verim, derimden önce ve derimden sonra meyvelerde bazı pomolojik özellikler incelenmiş ve sonuçlar açıkta yetiştiricilik ile kıyaslanmıştır. Araştırma bulguları, incelenen morfolojik özelliklerin önemli bir kısmının net örtü sistemi altında daha iyi sonuçlar verdiğini göstermiştir. Verimi doğrudan etkileyen tarak sayısı ve hevenk ağırlığg net örtü sistemi altında açığa göre daha yüksek kaydedilmiştir. Meyve fiziksel özelliklerinden parmak ağırlığı, parmak çevresi ve parmak uzunluğu değerleri net örtü sistemi altında daha yüksek belirlenmiştir. Sonuç olarak, net örtü sistemi açığa göre verim ve kalite özellikleri açısından daha iyi sonuç vermiştir.

\section{ARTICLE INFO}

Received 30 August 2019

Received in revised form 11 June 2020

Accepted 01 July 2020

\section{Keywords:}

Banana

Cover material

Cultivation system

Yield

Quality

\begin{abstract}
The cost of greenhouse construction is one of the most significant factors increasing the production cost in banana growing in Turkey. However, it is required to develop a contemporary system that should be alternative to the greenhouse in rugged terrain and economical in terms of the total cost in banana production, allowing the growers to use of rainwater especially during the rainy season. Due to these reasons, in this study, it is aimed to compare the net covering system providing the use of rain-water with open field production in the rugged terrain in which is not available to construct greenhouse due to the field structure. This experiment was conducted in Gazipaşa, Antalya locally in Yakacık between 2015 and 2016. In the study in which the 'Dwarf Cavendish' variety was used, the galvanized iron and monofilament white weaving net (with UV stabilization, 8-12\% shading, hail-resistant, and 25 mesh $10 \times 8$ pore width) were utilized as construction materials. In this study, some morphological characteristics of plants including stem round, stem length, the number of leaves and stem round of cluster, yield, and pomological characteristics of pre-harvested and post-harvested fruits were comparatively determined concerning the open field and net covering system. Research findings illustrated that the substantial part of morphological characteristics showed valuable results under the net covering system. In addition to this, the results indicated that the number of combs and weight of clusters directly affecting the yield was higher under the net covering system than the open field growing. Furthermore, it was determined that fruit physical characteristics involving the values of finger weight, finger around, and length were higher under the net covering system. As a consequence, the net covering system exhibited better results compared with the open field growing in terms of yield and quality features.
\end{abstract}




\section{Giriş}

Muz, dünyada yaygın olarak, tropik iklimin görüldüğü $20^{\circ}$ kuzey ve güney enlemleri arasında yetiştirilmektedir. Bu enlem dereceleri dışında kalan $\left(20^{\circ}\right.$ ve $30^{\circ}$ güney ve kuzey enlemleri arası) ülkelerde ise subtropik iklim koşularında yetiştirilmektedir (Stover ve Simmonds 1987). Ülkemizde ise muz yetiştiriciliğinin yapıldığ 1 lokasyonlar, kritik enlem derecesinin $\left(30^{\circ}\right)$ dahi dışında kalmakta ve ülkemizde kuzey enlem derecesi sınır $36^{\circ}$ olarak bildirilmiştir (Gübbük ve ark. 2010). Bununla birlikte, ülkemizde dekara verim, örtüaltı avantajından dolayı dünya ortalamasının üstünde seyretmektedir (Fao 2017). Zira dünyada, örtüaltı muz yetiştiriciliğinin verim ve kaliteyi olumu yönde etkilediği birçok çalışma ile desteklenmiștir (Galan Sauco ve ark. 1998; Eckstein ve ark. 1998a; Gubbuk ve Pekmezci 2004). Dünyada, net örtü sistemi altında gölge tülü ya da böcek tülü kullanımına yönelik muzda yapılan çalışmalar sınırlı sayıdadır. Bu konuda yapılan çalışmalara, başta İsrail olmak üzere, Mısır'da rastlanmış ve bu çalışmalarda, materyal özelliği, rengi ve delik çapına kadar bazı konularda hala açıklığa kavuşturulacak konular olduğu vurgulanmıştır (Refaie ve ark. 2012; Pirkner ve ark. 2014).

Örtüaltı muz yetiştiriciliğinde, girdi maliyetini arttıran en önemli unsurlardan birisi sera yapım maliyetidir. Net örtü sistemi (böcek tülü) altında yetiştiriciliğin ise seraya göre maliyetinin düşük olduğu ve daha ucuz teknolojiye ihtiyaç duyulduğu bildirilmiştir (Teitel ve ark. 2017). Aynı araştırmada, net örtü sistemi altında, yüksekliğin 4 ya da $6 \mathrm{~m}$ olarak inşa edilmesinin sıcaklık ve oransal nem açısından bir farklılık yaratmadığ 1 da kaydedilmiştir. Refaie ve ark. (2012), Mısır'da “'Grand Nain" muz çeşidinde iki farklı renge sahip böcek tülünün su tüketimi, vejetatif büyüme ve hevenk ağırlığı üzerine etkisini araştırmışlardır. Kullanılan böcek tüllerinden, kırmızı renge sahip olanda 1şık geçirgenliği \%30 ve siyahta ise $\% 45$ olarak bildirilmiştir. Yaz süresince, gölgelemenin açığa göre (örtü kullanılmayan) su tüketimini azalttığı, oransal nemi yükselttiği, hava sıcaklığını düşürdüğü, bitkilerin daha hızlı büyümesini sağladığı ve hevenk ağırlığını yükselttiği bildirilmiştir. Açık ile kıyaslandığında, gölgeleme ile su kullanım randımanı \%40 daha düşük (açıkta $740.3 \mathrm{~mm}$ ve uygulamalarda $521.8 \mathrm{~mm}$ ) saptanmıştır. Suyun etkin kullanımı açık ile kıyaslandığında, siyah böcek tülünde \%44.9-\%55.2, buna karşın kırmızı böcek tülünde ise $\% 73.9$ ve $\% 87.0$ oranında daha yüksek kaydedilmiştir. Pirkner ve ark. (2014), İsrail'de muz yetiştiriciliğinde farklı örtü materyalleri (dokuma ve örgü) ve gölgeleme yüzdesinin $(\% 8,10$ ve 13$)$ muz yetiştiriciliğinde kullanım olanaklarını araştırmışlardır. Bu amaçla yürütülen çalışmada, dokuma ve örgüde delik boyutları farklılık göstermiştir. Dokumada 2 x 3 ve 2 x 5 olmak üzere iki ve yine örgüde $2 \times 11$ ve 3 x 11 olmak üzere iki delik boyutu denenmiştir. Dokuma ve \%10 gölgeleme özelliğine sahip 2 × 3 $\mathrm{mm}$ ve $3 \times 11 \mathrm{~mm}$ delik boyutundaki materyaller, iklimsel veriler açısından kıyaslandığında; 2 × $3 \mathrm{~mm}$ delik boyutunda hava geçirgenliğinin daha düşük olması nedeniyle sera içinde oransal nem \%10 daha yüksek saptanmıştır. Araştırmada ayrıca, dokuma özelliğine sahip örtü materyalinde, buharlaşmanın daha düşük düzeyde olduğu kaydedilmiştir. Buna ilave olarak, hevenk oluşumu ve verim parametrelerinin örtü materyallerinden etkilenmediği bildirilmiştir. Araştırma sonucunda, \%10 gölgeleme özelliğine sahip dokuma örtü materyali tavsiye edilmiştir. Tanny ve ark. (2018), net örtü sistemi altında muz yetiştiriciliğin İsrail'de standart bir uygulama haline geldiğini ve net örtü sistemi altında yetiştiricilik ile verimin arttığını ve su kullanım randımanının daha yüksek olduğunu bildirmişlerdir. Haijun ve ark. (2015), net örtü sistemi altında bitkilerde terlemenin \%10 oranında düştüğü, Siqueira ve ark. (2012), açık ile kıyaslandığında net örtü sistemi altında su kullanım randımanının \%25 oranında daha yüksek olduğunu bildirmişlerdir.

Subtropik koşullarda yapılan muz yetiştiriciliğinde, sera örtü materyali olarak plastik kullanımına ilişkin yapılan çalışmalara da rastlanmış ve bu çalışmalarda da verimin açığa göre daha yüksek olduğu kaydedilmiştir. Nitekim Mendez Hernandez (1998), Kanarya Adaları'nda selekte edilen iki farklı muz klonu (Johson ve Brier) ile Grand Nain muz çeşidi üzerinde yaptıkları çalışmada, incelenen tüm kriterler açısından örtüaltı yetiştiriciliğinin açığa göre daha avantajlı olduğunu bildirmişlerdir. Benzer şekilde, Eckstein ve ark. (1998b), Güney Afrika'da, 'Williams', 'Chinese Cavendish', ve "Grand Nain"' Israel çeşitleri ile yürütülen çalışmada, örtüaltı yetiştiriciliğinde verimin açığa göre $\% 28$ oranında daha yüksek olduğunu belirlemişlerdir. Gubbuk ve ark. (2004), "Grand Nain", 'Petit Nain", 'Poyo", "'Williams"' ve "'Basrai", muz çeşitleri üzerinde, açıkta ve örtüaltında yürütükleri çalışmada, çeșitlere göre değişmekle birlikte verimi, örtüaltında açığa göre \%19-28 oranında daha yüksek belirlemişlerdir. Yine Gubbuk ve Pekmezci (2004) tarafindan, 'Dwarf Cavendish"' muz klonu üzerinde yürütülen çalışmada, hektardan elde edilen verim değeri örtüaltında açıktan daha yüksek belirlenmiş ve verim sırasıyla açıkta 42.8 ton ve örtüaltında 65.5 ton olarak saptanmıştır.

Örtüaltı yetiştiriciliği, muz yanında papaya gibi tropik meyve türlerinde, verim artış1 yanında hastalıkların taşınmasının (Papaya ring spot virüs hastalığı) önlenmesinde de kullanıldığ bildirilmiştir (Galan Sauco ve Rodriguez Pastor 2007, Martelleto ve ark. 2008). Martelleto ve ark. (2008), tropik koşullarda Papaya ringspot virüs (PRSV) hastalığından dolayı, papayayı subtropik koşullarda olduğu gibi örtüaltında (plastik, plastik+net, net) yetiştirilmesini tavsiye etmişlerdir. Galan Sauco (2002), tropik meyve türlerinin örtüaltı yetiştiricilik potansiyelini incelemiştir. Araştırıcı, papayanın çevre koşulları yetersiz olduğu zaman (özellikle $20^{\circ} \mathrm{C}$ 'nin altında) vegetatif gelişme, çiçeklenme ve meyve tutumunun olumsuz yönde etkilendiğini bildirmiştir. $\mathrm{Bu}$ sorunların, örtüaltı yetiştiriciliği ile önlenebileceği bildirilmiştir. Bu nedenle dünyada papaya yetiştiriciliğinin Kanarya adaları, Japonya ve İsrail'de ticari anlamda örtüaltında yapıldığ kaydedilmiştir.

$\mathrm{Bu}$ çalışmada, muz yetiştiriciliğinde sera kurulumuna elverişli olmayan eğimli arazilerde net örtü sisteminin açığa göre verim ve kalite açısından gösterdiği performansların incelenmesi amaçlanmıştır.

\section{Materyal ve Yöntem}

\subsection{Materyal ve dikim hazırlığ}

$\mathrm{Bu}$ çalışma, Mart 2015-Şubat 2016 yılları arasında Antalya'nın Gazipaşa Yakacık mevkiinde, homojen bir arazi yapısına sahip, yüzde \%25-30 eğime sahip, dört yıllık bir muz plantasyonunda yürütülmüştür. Olgunlaştırma ve pomolojik analizler Akdeniz Üniversitesi Bahçe Bitkileri Bölümünde yapılmıştır. Araştırmada çeşit olarak 'Dwarf Cavendish'” muz çeşidi kullanılmış ve bitkiler ocak şeklinde (2 bitki/ocak) dikilmiştir (1600 bitki ha $\left.{ }^{-1}\right)$. Bitkiler damla sulama sistemi ile sulanmış ve gübreleme Gubbuk ve Pekmezci (2004)'e göre uygulanmıştır. 


\subsubsection{Kullanilan konstrüksiyon malzemeleri}

Konstrüksiyon olarak galvanizli boru kullanılmış ve sera, orta kısmının yüksekliği $7 \mathrm{~m}$ ve yan yüksekliği ise $5.5 \mathrm{~m}$ olacak şekilde planlanmıştır. Net örtü sistemi olarak ise UV stabilize, \%8-12 gölgeleme özelliğinde, 25 mesh 10X8 gözenek genişliğinde beyaz böcek tülü kullanılmıştır.

\subsubsection{Sicaklık ve oransal nem değerleri}

Sıcaklık ve oransal nem saat başı kaydedilmiştir. Açıkta sezon boyunca minimum sicaklik, $10.57-24.63^{\circ} \mathrm{C}$, ortalama sicaklık $14.02-28.71^{\circ} \mathrm{C}$ ve maksimum sicaklık $20.21-34.06^{\circ} \mathrm{C}$ ve net örtü sistemi altında sezon boyunca minimum sıcaklık $10.09-23.47^{\circ} \mathrm{C}$, ortalama sicaklık $14.00-28.66^{\circ} \mathrm{C}$ ve maksimum $21.40-35.19^{\circ} \mathrm{C}$ olarak kaydedilmiştir. Oransal nem değeri ise açıta minimum \%40.72-51.79, ortalama \%56.84-71.18 ve maksimum \%71.24-85.14 ve net örtü sistemi altında minimum oransal nem değeri \%34.86-44.81, ortalama oransal nem değeri \%52.14-63.86, maksimum oransal nem değeri \%67.61-81.75 arasında kaydedilmiştir.

\subsection{Metot}

Araştırmada, uygulamaların bitki morfolojik (bitki boyu, yalancı gövde yüksekliği ve çevresi, toplam ve aktif yaprak sayıs1), verim bileşenleri (tarak sayısı, toplam parmak sayısı, hevenk ağırlığı) üzerine etkileri incelenmiştir. Parametrelere ait ölçüm ve gözlemler, Gübbük ve ark. (2010) ile Altınkaya (2016)'ya göre yapılmıştır. Hevenklerin derimi, parmaklarda köşeliliğin üçte iki oranında kaybolduğu zamanda yapılmış ve meyveler $16^{\circ} \mathrm{C}$ sicaklık ve $\% 90$ oransal nemde olgunlaştırılmıştır (Gübbük ve ark. 2010). Etilen uygulamasından sonra olgunlaşma periyodunda meyve kabuk rengindeki değişimler Minolta marka renk ölçme aleti ile $\mathrm{L}^{*}$, $a^{*}$ ve $b^{*}$ değerleri cinsinden belirlenmiş ve kroma (C) ile hue $\left(h^{\circ}\right)$ değerleri aşağıdaki formüllere göre hesaplanmıştır (McGuire 1992).

$$
\begin{aligned}
& C:\left(a^{2}+b^{2}\right), \\
& h^{\circ}: \tan ^{-1}(b / a) .
\end{aligned}
$$

Parmak ağırlığı, meyve kabuk kalınlığı, meyve eti setliği, kabuk oranı ve suda çözünebilir kuru madde (SÇKM) düzeyi ile kabuk rengi değişimi $\left(\mathrm{C}\right.$ ve $\left.\mathrm{h}^{\circ}\right)$ olgunlaşmanın 6 no'lu aşamasında belirlenmiştir (Kader 2002).

\subsection{1. İstatistiksel analiz}

Araştırma 3 yinelemeli ve her yinelemede arazi ve meyve ile ilgili çalışmalarda 10 bitki/meyve olacak şekilde tesadüf parselleri deneme desenine göre planlanmıştır. Tanımlayıcı istatistikler ortalama değerleri ile verilmiştir. Normallik dağılımı Shapiro Wilk testi ile test edilmiştir. Normal dağılan değişkenler için bağımsız $t$ testi (independent $t$ test), normal dağılıma uymayanlar için Mann-Whitney U testi kullanılmıştır. $\mathrm{P}<0.05$ istatistiksel olarak anlamlı kabul edilmiştir. Analizler SPSS 23 programı kullanılarak yapılmıştır. Araştırmada ayrıca açık ve net örtü sistemi altında incelenen bazı özellikler arasındaki ilişkiler Minitab 19 istatistik programı kullanılarak korelasyon analizi ile belirlenmiştir.

\section{Bulgular ve Tartışma}

Açık ve net örtü sistemi altında saptanan bitki boyu, yalancı gövde yüksekliği ve çevresi ile toplam ve aktif yaprak sayılarına ait bulgular Çizelge 1'de verilmiştir. İncelenen kriterlerden gövde çevresi dışında kalan tüm kriterler üzerine uygulamaların etkisi istatistiksel olarak önemli bulunmuş ve net örtü sistemi altında sonuçlar açıktan daha yüksek saptanmıştır. Bitki boyu net örtü sistemi altında $390.95 \mathrm{~cm}$ olarak ölçülürken, açıkta $365.19 \mathrm{~cm}$ olarak kaydedilmiştir. Benzer durum, yalancı gövde yüksekliği bakımından da tespit edilmiş olup, değerler açık ve net örtü sistemi için sırasıyla $146.15 \mathrm{~cm}$ ve $172.60 \mathrm{~cm}$ olarak kaydedilmiştir. İncelenen diğer kriterlerden toplam ve aktif yaprak sayıları, net örtü sistemi altında daha yüksek belirlenmiştir. Toplam yaprak sayısı açıkta 24.86 , net örtü sistemi altında 31.82 adet ve aktif yaprak sayıs1 ise açıkta 8.06 ve net örtü sistemi altında ise 12.11 adet arasında değişim göstermiştir. Net örtü sistemi altında gövde yüksekliği, toplam ve aktif yaprak sayısının daha yüksek belirlenmesi, özellikle rüzgarın etkisinin net örtü sistemi altında daha düşük olmasından ve bu durumun bitki büyüme ve gelişmesi üzerine olumlu yönde yansımasından kaynaklanmış olabilir. Refaie ve ark. (2012), Grand Nain muz çeşidi üzerinde yürüttükleri çalışmada, böcek tülü rengi çalışmamızdan farklı olmakla birlikte, siyah ve kırmızı böcek tülü kullanımın açığa göre bulgularımızda olduğu gibi bitki büyüme ve gelişmesini olumlu yönde etkilediğini bildirmişlerdir.

Hevenk sapı çevresi, tarak sayısı, toplam parmak sayısı ve hevenk ağırlığı ile hevenk oluşumundan derime kadar geçen süre üzerine uygulamaların etkisi Çizelge 2'de verilmiş̧ir. Bu çizelgede görüldüğü gibi uygulamaların sadece toplam parmak sayısı ve hevenk oluşumundan derime kadar geçen süreyi istatistiksel olarak etkilediği görülmektedir. Tarak sayısı istatiksel olarak farklı çıkmamakla beraber net örtü sistemi altında daha yüksek kaydedilmiştir. Zira net örtü sistemi altında, 11.44 adet ile açıktan daha yüksek kaydedilmiştir. İncelenen kriterlerden hevenk sap1 çevresi değeri, tarak sayısında olduğu gibi her iki uygulamada birbirine oldukça

Çizelge 1. Açık ve net örtü sistemi altında morfolojik özelliklere ait sonuçlar.

Table 1. Results of morphological features in open-field and net covering system.

\begin{tabular}{cccccc}
\hline Uygulamalar & $\begin{array}{c}\text { Bitki Boyu } \\
(\mathrm{cm})\end{array}$ & $\begin{array}{c}\text { Gövde Yükseklï̆i } \\
(\mathrm{cm})\end{array}$ & $\begin{array}{c}\text { Gövde Çevresi } \\
(\mathrm{cm})\end{array}$ & $\begin{array}{c}\text { Toplam Yaprak Sayıs } \\
(\mathrm{adet})\end{array}$ & $\begin{array}{c}\text { Aktif Yaprak Sayıs1 } \\
(\text { adet })\end{array}$ \\
\hline Açı (Open-field) & $365.19 \mathrm{~b}$ & $146.15 \mathrm{~b}$ & 73.10 & $24.86 \mathrm{~b}$ & $8.06 \mathrm{~b}$ \\
Net (Net) & $390.95 \mathrm{a}$ & $172.60 \mathrm{a}$ & 74.75 & $31.82 \mathrm{a}$ & $12.11 \mathrm{a}$ \\
$\mathrm{P}$ & $0.004^{2}$ & $<0.0001 * 1$ & Ö.D. & $<0.0001 * 1$ & $<0.0001 * 2$ \\
\hline
\end{tabular}

*Açık ve net uygulama ortalamaları istatistiksel olarak birbirinden farklıdır (p $\leq 0.05)$. **ö.D. istatistiksel olarak önemli değil. 1: Bağımsız t testi, 2: Mann-Whitney U test kullanılmıştır. 
yakın saptanmış ve $23.50 \mathrm{~cm}$ ile $24.25 \mathrm{~cm}$ arasında değişim göstermiştir. Hevenk ağırlığı ve buna bağlı olarak verimi doğrudan etkileyen toplam parmak sayısı ise 224.10 adet ile net örtü sistemi altında daha yüksek kaydedilmiştir. Hevenk ağırlı̆g 30 kg'a ve açıkta ise 27 kg'a yakın kaydedilmiştir. Hevenk oluşumundan derime kadar geçen süre ise net örtü sistemi altında yaklaşık 10 gün daha kısa saptanmıştır. Araştırma bulgularında, net örtü sistemi altında meyve gelişim süresinin daha kısa ve özellikle toplam parmak sayısının daha yüksek saptanması, incelenen diğer morfolojik özelliklerde olduğu gibi netin özellikle yapraklarda yırtılmaları engellemesi ve bitkilerde fotosentezi olumlu yönde etkilemesinden kaynaklandığı düşünülmektedir. Refaie ve ark. (2012), iki farklı renkteki (kırmızı ve siyah) böcek tülünde, bulgularımızda olduğu gibi hevenk ağırlığını açığa göre daha yüksek belirlemişlerdir. Bunun yanında net örtü sistemi altında maksimum sıcaklığın yüksek olması, açığa göre net örtü sistemi altında verimi arttırdığı görüşündeyiz. Tanny ve ark. (2018), İsrail'de yürüttükleri çalışmada net örtü sistemi altında verimin daha yüksek olduğunu kaydetmişlerdir. Parmak çevresi, parmak uzunluğu, parmak çapı ile olgunlaştırmadan önce ve sonra parmak ağırlığı üzerine uygulamaların etkisi Çizelge 3'te verilmiştir. Uygulamaların parmak çevresi ve uzunluğu ile olgunlaştırmadan önce ve sonra parmak ağırlı̆̆ üzerine etkileri istatistiksel olarak önemli bulunmuştur. Parmak çevresi ve parmak uzunluğu net örtü sistemi altında, açıktan daha yüksek belirlenmiştir. Parmak çapı ise her iki uygulamada birbirine yakın belirlenmiştir. Olgunlaştırmadan önce ve sonra saptanan parmak ağırlığı yine net örtü sistemi altında daha yüksek kaydedilmiştir. Verimi doğrudan etkileyen parmak ağırlığ hem olgunlaştırma ve hem de olgunlaştırma sonrası daha yüksek düzeyde belirlenmiştir. Bulgularımızda olduğu gibi Refaie ve ark. (2012) parmak ağırlığını açığa göre siyah ve kırmızı olmak üzere net örtü sistemi altında daha yüksek kaydetmişlerdir. Buna karşın, Pirkner ve ark (2014), farklı özellikteki örtü materyallerinin parmak ağırlığı, uzunluğu ve çevresini etkilemediğini bildirmişlerdir.

İncelenen kriterlerden kabuk kalınlığı ve meyve eti setliği ile SÇKM üzerine etkileri istatistiksel olarak önemli ve meyve kabuk oranı ve meyve eti oranı üzerine etkisi ise istatistiksel olarak önemsiz bulunmuştur (Çizelge 4). Meyve kabuk kalınlığı ve meyve eti sertliği ile SÇKM oranı açıkta daha yüksek saptanmıștır. Uygulamalara göre değișmekle birlikte, meyve kabuk kalınlığ $2.16 \mathrm{~mm}$ ile $2.30 \mathrm{~mm}$ ve meyve eti setliği ise $1.63 \mathrm{~kg} \mathrm{~cm}^{-2}$ ile $1.77 \mathrm{~kg} \mathrm{~cm}^{-2}$ arasında değişim göstermiştir. Meyve eti sertliğinin açıkta daha yüksek olmasına neden olarak, açıkta kabuk kalınlığının daha yüksek kaydedilmesi gösterilebilir. SÇKM miktarı açıkta yetiştiricilikte net örtü sistemi altından daha yüksek saptanmıştır. Her iki uygulamada kalite kriterleri arasında kaynaklanan bu farklılıklar, her iki yetiştirme ortamında gece gündüz arasında kaydedilen iklimsel faktörlerdeki dalgalanmalardan kaynaklanabileceği sonucuna varılmıştır. Zira net örtü sistemi altında sicaklık ve oransal nemde dalgalanma, açığa göre daha düşük kaydedilmiştir. Bununla birlikte, açıkta oransal nem değerleri nete göre daha yüksek saptanmıştır. Buna neden olarak da araştırmada kullanılan net örtü sisteminde mesh boyutunun düşük olması gösterilmiştir. $\mathrm{Bu}$ durum ise havada oluşan çiğin örtü içerisine alınımını engellenmiştir. Net örtü sistemi altında yapılan çalışmalarda, olgunlaşma sonucu kalite kriterleri üzerine örtü materyallerinin etkisi konusunda herhangi bir çalışmaya rastlanmadı̆̆ından dolayı, sonuçlar diğer çalışmalar ile karşılaştırılamamıştır.

Açık ve net örtü sistemi altında olgunlaştırma öncesi C değeri (parlaklık) üzerine etkisi istatistiksel olarak önemli, olgunlaştırma sonrası C değeri (parlaklık) üzerine etkisi istatistiksel olarak önemsiz bulunmuştur (Çizelge 5). Yeşil rengin sarıya dönüşümünü gösteren $\mathrm{h}^{\circ}$ değerleri de istatistiksel olarak önemsiz bulunmuş her iki uygulamada da birbirine yakın belirlenmiștir. Albeni açısından düşündüğümüzde, renk değerlerinde özellikle olgunlaşma sonrası daha önemlidir. Bu nedenle bulgularımız renk açısından değerlendirildiğinde, olgunlaştırma sonrası farklılığın belirlenmemesi, renk üzerine uygulamaların etkili olmadığını göstermektedir. Olgunlaştırmadan sonra saptanan $\mathrm{C}$ ve $\mathrm{h}^{\circ}$ değerleri, Balkıç ve ark. (2017) tarafindan yapılan çalışma ile benzer bulunmuştur.

Açıkta yetiştiricilikte, verimi direkt olarak etkileyen hevenk ağırlığı ile tarak sayısı arasında negatif bir korelasyon belirlenmiştir (Çizelge 6). Hevenk ağırlığı ile morfolojik özelliklerden gövde çevresi ve gövde yüksekliği arasında ise yine negatif yönde ve düşük düzeyde bir korelasyon saptanmıştır. Muzda kalite kriterleri arasında, parmak uzunluğu en önemli parametredir. Zira ihracatta parmak uzunluğu dikkate alınan en önemli özelliktir. Parmak uzunluğuyla incelenen özelliklerden parmak çevresi, parmak çapı, parmak ağırlığı ve meyve eti ağırlığı arasında pozitif bir korelasyon kaydedilmiştir.

Net örtü sisteminde, hevenk ağırlığı ile tarak sayısı arasında pozitif bir korelasyon belirlenmiştir (Çizelge 7). Açıkta yetiştiricilikten farklı olarak, net örtü sistemi altında hevenk ağırlığı ile verim parametrelerinden parmak çevresi arasında negatif bir korelasyon kaydedilmiştir. Net örtü sistemi altında açıktan farklı olarak korelasyon analizinde, hevenk ağırlığı ile morfolojik özellikler arasında bir korelasyon belirlenmemiştir. Parmak uzunluğu ile parmak çevresi, parmak çapı, parmak ağırlığı ve meyve eti ağırlığı arasında açıkta olduğu gibi pozitif bir korelasyon belirlenmiştir.

\section{Sonuc}

Araştırma sonuçları, örtü materyali olarak böcek tülü kullanımının açıktaki yetiştiriciliğe göre verim ve kalite özelliklerini olumlu yönde etkilediğini göstermiştir. Bununla birlikte, araştırma sonuçları daha önceki yıllarda yaptığımız örtü materyali olarak plastik kullanılan çalışmalar ile kıyaslandığında, verimin net örtü sistemi altında yetiştiricilikte daha düşük olduğunu söyleyebiliriz. Bu nedenle, daha sonra yapılacak çalışmalarda daha iyi sonuçlar alabilmek için net örtü sistemi altında oransal nemin arttırılması amacı ile sera içerisinde sisleme yapılması, ayrıca daha geniş gözenekli, farklı renkte ve dokuma özelliklerine sahip örtü materyallerinin kullanılması tavsiye edilmiştir. 
Çizelge 2. Açık ve net örtü sistemi altında hevenk özellikleri, hevenk ağıllı̆̆ı ve meyve gelişme süresine ilişkin sonuçlar.

Table 2. Results of bunch features, bunch weight and days from bunch emerge to harvest in in open-field and net covering system.

\begin{tabular}{cccccc}
\hline Uygulamalar & $\begin{array}{c}\text { Hevenk Sapı Çevresi } \\
(\mathrm{cm})\end{array}$ & $\begin{array}{c}\text { Tarak Sayısı } \\
(\mathrm{adet})\end{array}$ & $\begin{array}{c}\text { Toplam Parmak Sayısı } \\
(\text { adet/hevenk) }\end{array}$ & $\begin{array}{c}\text { Hevenk } \\
\text { Ağırlığı }(\mathrm{kg})\end{array}$ & $\begin{array}{c}\text { Hevenk Oluşumundan Derime Kadar } \\
\text { Geçen Süre (gün) }\end{array}$ \\
\hline Açık (Open-Field) & 24.25 & 10.76 & $199.94 \mathrm{~b}$ & $26.84 \mathrm{~b}$ & $153.87 \mathrm{a}$ \\
Net (Net) & 23.50 & 11.44 & $224.10 \mathrm{a}$ & $29.93 \mathrm{a}$ & $143.81 \mathrm{~b}$ \\
$\mathrm{P}$ & $0.211^{* 2}$ & $0.084^{* 2}$ & $0.013^{* 2}$ & $<0.0001^{* 2}$ & $<0.0001^{* 1}$
\end{tabular}

*Açık ve net uygulama ortalamaları istatistiksel olarak birbirinden farklıdır ( $\mathrm{p} \leq 0.05)$. 1: Bağımsız t testi, 2: Mann-Whitney $\mathrm{U}$ test kullanılmıştır.

Çizelge 3. Açık ve net örtü sistemi altında meyve fiziksel özelliklerine ait sonuçlar.

Table 3. Results of fruit physical features in open-field and net covering system.

\begin{tabular}{|c|c|c|c|c|c|}
\hline Uygulamalar & $\begin{array}{l}\text { Parmak Çevresi } \\
(\mathrm{cm})\end{array}$ & $\begin{array}{l}\text { Parmak Uzunluğu } \\
(\mathrm{cm})\end{array}$ & $\begin{array}{l}\text { Parmak Çap1 } \\
(\mathrm{mm})\end{array}$ & $\begin{array}{l}\text { Olgunlaştırmadan Önce } \\
\text { Parmak Ağırlığ } 1 \text { (g) }\end{array}$ & $\begin{array}{l}\text { Olgunlaştırmadan Sonra } \\
\text { Parmak Ağırlığ }(\mathrm{g}) \\
\end{array}$ \\
\hline Açık (Open-field) & $12.10 \mathrm{~b}$ & $19.94 \mathrm{~b}$ & 34.23 & $95.81 \mathrm{~b}$ & $89.20 \mathrm{~b}$ \\
\hline Net (Net) & $12.65 \mathrm{a}$ & $22.69 \mathrm{a}$ & 34.75 & $101.98 \mathrm{a}$ & $94.52 \mathrm{a}$ \\
\hline $\mathrm{P}$ & $<0.0001^{* 1}$ & $<0.0001^{* 1}$ & $0.774^{* 2}$ & $0.039^{* 1}$ & $0.048^{* 1}$ \\
\hline
\end{tabular}

*Açık ve net uygulama ortalamaları istatistiksel olarak birbirinden farklıdır (p $\leq 0.05)$. **Ö.D. istatistiksel olarak önemli değil. 1: Bağımsız t testi, 2: Mann-Whitney U test kullanılmıştır.

Çizelge 4. Açık ve net örtü sistemi altında pomolojik özelliklere ait sonuçlar.

Table 4. Results of pomological features in open-field and net covering system.

\begin{tabular}{|c|c|c|c|c|c|}
\hline Uygulamalar & $\begin{array}{l}\text { Kabuk Kalınlığ } \\
(\mathrm{mm})\end{array}$ & $\begin{array}{c}\text { Meyve Eti Sertliği } \\
\left(\mathrm{kg} \mathrm{cm}^{-2}\right)\end{array}$ & $\begin{array}{c}\text { Meyve Kabuk Oranı } \\
(\%)\end{array}$ & $\begin{array}{c}\text { Meyve Et Oranı } \\
(\%)\end{array}$ & $\begin{array}{c}\text { SÇKM } \\
(\%)\end{array}$ \\
\hline Açık Open-field) & $2.30 \mathrm{a}$ & $1.77 \mathrm{a}$ & 35.32 & 64.68 & $20.06 \mathrm{a}$ \\
\hline Net (Net) & $2.16 \mathrm{~b}$ & $1.63 \mathrm{~b}$ & 36.58 & 63.42 & $19.58 \mathrm{~b}$ \\
\hline $\mathrm{P}$ & $<0.0001^{* 1}$ & $<0.0001^{* 1}$ & Ö.D. & Ö.D. & $<0.0001^{* 2}$ \\
\hline
\end{tabular}

*Açık ve net uygulama ortalamaları istatistiksel olarak birbirinden farklıdır (p $\leq 0.05)$. **Ö.D. istatistiksel olarak önemli değil. 1: Bağımsız t testi, 2: Mann-Whitney U test kullanılmıştır.

Çizelge 5. Açık ve net örtü sistemi altında olgunlaşma öncesi ve sonrası C renk ve $h^{\circ}$ açı değerlerine ait sonuçlar.

Table 5. Results of $\mathrm{C}$ and $h^{\circ}$ angle values before and after ripening in open-field and net covering system.

\begin{tabular}{cccc}
\hline Uygulamalar & \multicolumn{2}{c}{ Olgunlaştırma Öncesi } & \multicolumn{2}{c}{ Olgunlaştırma Sonrası } \\
\cline { 2 - 4 } Açık (Open-field) & $\mathrm{C}$ & $h^{\circ}$ & $\mathrm{C}$ \\
Net (Net) & $43.64 \mathrm{a}$ & 117.08 & 46.43 \\
$\mathrm{P}$ & $42.82 \mathrm{~b}$ & 117.07 & 46.17 \\
\hline
\end{tabular}

*Açık ve net uygulama ortalamaları istatistiksel olarak birbirinden farklıdır (p $\leq 0.05)$. **Ö.D. istatistiksel olarak önemli değil. 1: Bağımsız t testi, 2: Mann-Whitney U test kullanılmıştır. 
Çizelge 6. Açıkta yetiştiricilikte incelenen parametrelere ait korelasyon analiz sonuçları.

Table 6. Results of correlation analysis belong to examined parameters in open-field growing.

\begin{tabular}{|c|c|c|c|c|c|c|c|c|c|c|c|c|c|c|c|c|}
\hline Değişkenler & BB & GÇ & GY & TYS & AYS & HSÇ & TS & TPS & HA & $\mathrm{PU}$ & PÇ & PÇA & PA & MEA & KK & MES \\
\hline Bitki Boyu (BB) & - & - & - & - & - & - & - & - & - & - & - & - & - & - & - & - \\
\hline Gövde Çevresi (GÇ) & $\begin{array}{l}0.715 \\
(* * *)\end{array}$ & - & - & - & - & - & - & - & - & - & - & - & - & - & - & - \\
\hline Gövde Yüksekliği (GY) & $\begin{array}{c}0.309 \\
\text { (Ö.D.) }\end{array}$ & $\begin{array}{c}0.346 \\
(*)\end{array}$ & - & - & - & - & - & - & - & - & - & - & - & - & - & - \\
\hline Toplam Yaprak Sayısı (TYS) & $\begin{array}{c}0.189 \\
\text { (Ö.D.) }\end{array}$ & $\begin{array}{c}0.059 \\
\text { (Ö.D.) }\end{array}$ & $\begin{array}{c}0.201 \\
\text { (Ö.D.) }\end{array}$ & - & - & - & - & - & - & - & - & - & - & - & - & - \\
\hline Aktif Yaprak Sayısı (AYS) & $\begin{array}{c}0.052 \\
\text { (Ö.D.) }\end{array}$ & $\begin{array}{l}-0.052 \\
\text { (Ö.D.) }\end{array}$ & $\begin{array}{l}-0.311 \\
\text { (Ö.D.) }\end{array}$ & $\begin{array}{c}0.440 \\
(* *)\end{array}$ & & - & - & - & - & - & - & - & - & - & - & - \\
\hline Hevenk Sapı Çevresi (HSÇ) & $\begin{array}{l}0.738 \\
(* * *)\end{array}$ & $\begin{array}{l}0.663 \\
(* * *)\end{array}$ & $\begin{array}{c}0.376 \\
(*)\end{array}$ & $\begin{array}{c}0.065 \\
\text { (Ö.D.) }\end{array}$ & $\begin{array}{c}0.068 \\
\text { (Ö.D.) }\end{array}$ & - & - & - & - & - & - & - & - & - & - & - \\
\hline Tarak Sayısı (TS) & $\begin{array}{l}0.759 \\
(* * *)\end{array}$ & $\begin{array}{l}0.665 \\
(* * *)\end{array}$ & $\begin{array}{c}0.439 \\
(* *)\end{array}$ & $\begin{array}{c}0.203 \\
\text { (Ö.D.) }\end{array}$ & $\begin{array}{c}0.012 \\
\text { (Ö.D.) }\end{array}$ & $\begin{array}{l}0.804 \\
(* * *)\end{array}$ & - & - & - & - & - & - & - & - & - & - \\
\hline Toplam Parmak Sayısı (TPS) & $\begin{array}{l}0.695 \\
(* * *)\end{array}$ & $\begin{array}{l}0.663 \\
(* * *)\end{array}$ & $\begin{array}{c}0.426 \\
(*)\end{array}$ & $\begin{array}{c}0.168 \\
\text { (Ö.D.) }\end{array}$ & $\begin{array}{c}0.069 \\
\text { (Ö.D.) }\end{array}$ & $\begin{array}{l}0.782 \\
(* * *)\end{array}$ & $\begin{array}{l}0.768 \\
(* * *)\end{array}$ & - & - & - & - & - & - & - & - & - \\
\hline Hevenk Ağırlığı (HA) & $\begin{array}{l}-0.322 \\
\text { (Ö.D.) }\end{array}$ & $\begin{array}{c}-0.355 \\
(*)\end{array}$ & $\begin{array}{c}-0.354 \\
(*)\end{array}$ & $\begin{array}{l}-0.205 \\
\text { (Ö.D.) }\end{array}$ & $\begin{array}{l}-0.018 \\
\text { (Ö.D.) }\end{array}$ & $\begin{array}{l}-0.307 \\
\text { (Ö.D.) }\end{array}$ & $\begin{array}{c}-0.523 \\
(* *)\end{array}$ & $\begin{array}{l}-0.254 \\
\text { (Ö.D.) }\end{array}$ & - & - & - & - & - & - & - & - \\
\hline Parmak Uzunluğu (PU) & $\begin{array}{c}0.160 \\
\text { (Ö.D.) }\end{array}$ & $\begin{array}{c}0.073 \\
\text { (Ö.D.) }\end{array}$ & $\begin{array}{c}0.149 \\
\text { (Ö.D.) }\end{array}$ & $\begin{array}{l}-0.004 \\
\text { (Ö.D.) }\end{array}$ & $\begin{array}{l}0.038 \\
\text { (Ö.D.) }\end{array}$ & $\begin{array}{l}-0.027 \\
\text { (Ö.D.) }\end{array}$ & $\begin{array}{c}0.042 \\
\text { (Ö.D.) }\end{array}$ & $\begin{array}{c}0.061 \\
\text { (Ö.D.) }\end{array}$ & $\begin{array}{c}0.121 \\
\text { (Ö.D.) }\end{array}$ & - & - & - & - & - & - & - \\
\hline Parmak Çevresi (PÇ) & $\begin{array}{c}0.188 \\
\text { (Ö.D.) }\end{array}$ & $\begin{array}{c}0.008 \\
\text { (Ö.D.) }\end{array}$ & $\begin{array}{c}0.161 \\
\text { (Ö.D.) }\end{array}$ & $\begin{array}{c}0.247 \\
\text { (Ö.D.) }\end{array}$ & $\begin{array}{c}0.169 \\
\text { (Ö.D.) }\end{array}$ & $\begin{array}{c}0.108 \\
\text { (Ö.D.) }\end{array}$ & $\begin{array}{c}0.105 \\
\text { (Ö.D.) }\end{array}$ & $\begin{array}{c}0.026 \\
\text { (Ö.D.) }\end{array}$ & $\begin{array}{c}0.003 \\
\text { (Ö.D.) }\end{array}$ & $\begin{array}{l}0.791 \\
(* * *)\end{array}$ & - & - & - & - & - & - \\
\hline Parmak Çapı (PÇA) & $\begin{array}{l}-0.025 \\
\text { (Ö.D.) }\end{array}$ & $\begin{array}{l}-0.022 \\
\text { (Ö.D.) }\end{array}$ & $\begin{array}{c}0.237 \\
\text { (Ö.D.) }\end{array}$ & $\begin{array}{c}0.230 \\
\text { (Ö.D.) }\end{array}$ & $\begin{array}{c}0.156 \\
\text { (Ö.D.) }\end{array}$ & $\begin{array}{l}-0.025 \\
\text { (Ö.D.) }\end{array}$ & $\begin{array}{l}-0.046 \\
\text { (Ö.D.) }\end{array}$ & $\begin{array}{l}-0.090 \\
\text { (Ö.D.) }\end{array}$ & $\begin{array}{l}-0.117 \\
\text { (Ö.D.) }\end{array}$ & $\begin{array}{l}0.623 \\
(* * *)\end{array}$ & $\begin{array}{l}0.654 \\
(* * *)\end{array}$ & - & - & - & - & - \\
\hline Parmak Ağırlığı (PA) & $\begin{array}{l}-0.059 \\
\text { (Ö.D.) }\end{array}$ & $\begin{array}{l}-0.088 \\
\text { (Ö.D.) }\end{array}$ & $\begin{array}{c}0.249 \\
\text { (Ö.D.) }\end{array}$ & $\begin{array}{c}0.035 \\
\text { (Ö.D.) }\end{array}$ & $\begin{array}{l}-0.021 \\
\text { (Ö.D.) }\end{array}$ & $\begin{array}{l}-0.103 \\
\text { (Ö.D.) }\end{array}$ & $\begin{array}{c}0.016 \\
\text { (Ö.D.) }\end{array}$ & $\begin{array}{l}-0.029 \\
\text { (Ö.D.) }\end{array}$ & $\begin{array}{l}-0.097 \\
\text { (Ö.D.) }\end{array}$ & $\begin{array}{l}0.799 \\
(* * *)\end{array}$ & $\begin{array}{l}0.781 \\
(* * *)\end{array}$ & $\begin{array}{l}0.687 \\
(* * *)\end{array}$ & - & - & - & - \\
\hline Meyve Eti Ağırlığı (MEA) & $\begin{array}{c}0.083 \\
\text { (Ö.D.) }\end{array}$ & $\begin{array}{l}-0.061 \\
\text { (Ö.D.) }\end{array}$ & $\begin{array}{l}-0.010 \\
\text { (Ö.D.) }\end{array}$ & $\begin{array}{c}0.025 \\
\text { (Ö.D.) }\end{array}$ & $\begin{array}{c}0.013 \\
\text { (Ö.D.) }\end{array}$ & $\begin{array}{c}0.007 \\
\text { (Ö.D.) }\end{array}$ & $\begin{array}{c}0.042 \\
\text { (Ö.D.) }\end{array}$ & $\begin{array}{c}-0.090 \\
\text { (Ö.D.) }\end{array}$ & $\begin{array}{c}0.009 \\
\text { (Ö.D.) }\end{array}$ & $\begin{array}{l}0.782 \\
(* * *)\end{array}$ & $\begin{array}{l}0.789 \\
(* * *)\end{array}$ & $\begin{array}{l}0.644 \\
(* * *)\end{array}$ & $\begin{array}{l}0.798 \\
(* * *)\end{array}$ & - & - & - \\
\hline Kabuk Kalınlığı (KK) & $\begin{array}{l}-0.222 \\
\text { (Ö.D.) }\end{array}$ & $\begin{array}{l}-0.259 \\
\text { (Ö.D.) }\end{array}$ & $\begin{array}{l}-0.192 \\
\text { (Ö.D.) }\end{array}$ & $\begin{array}{l}-0.227 \\
\text { (Ö.D.) }\end{array}$ & $\begin{array}{c}0.289 \\
\text { (Ö.D.) }\end{array}$ & $\begin{array}{l}-0.058 \\
\text { (Ö.D.) }\end{array}$ & $\begin{array}{l}-0.166 \\
\text { (Ö.D.) }\end{array}$ & $\begin{array}{l}-0.309 \\
\text { (Ö.D.) }\end{array}$ & $\begin{array}{l}-0.050 \\
\text { (Ö.D.) }\end{array}$ & $\begin{array}{c}0.013 \\
\text { (Ö.D.) }\end{array}$ & $\begin{array}{c}0.015 \\
\text { (Ö.D.) }\end{array}$ & $\begin{array}{c}0.094 \\
\text { (Ö.D.) }\end{array}$ & $\begin{array}{c}0.032 \\
\text { (Ö.D.) }\end{array}$ & $\begin{array}{c}0.049 \\
\text { (Ö.D.) }\end{array}$ & - & - \\
\hline Meyve Eti Sertliği (MES) & $\begin{array}{l}-0.165 \\
\text { (Ö.D.) }\end{array}$ & $\begin{array}{l}-0.179 \\
\text { (Ö.D.) }\end{array}$ & $\begin{array}{l}-0.024 \\
\text { (Ö.D.) }\end{array}$ & $\begin{array}{l}-0.049 \\
\text { (Ö.D.) }\end{array}$ & $\begin{array}{l}-0.017 \\
\text { (Ö.D.) }\end{array}$ & $\begin{array}{l}-0.121 \\
\text { (Ö.D.) }\end{array}$ & $\begin{array}{l}-0.251 \\
\text { (Ö.D.) }\end{array}$ & $\begin{array}{l}-0.197 \\
\text { (Ö.D.) }\end{array}$ & $\begin{array}{c}0.134 \\
\text { (Ö.D.) }\end{array}$ & $\begin{array}{c}0.157 \\
\text { (Ö.D.) }\end{array}$ & $\begin{array}{c}0.133 \\
\text { (Ö.D.) }\end{array}$ & $\begin{array}{c}0.260 \\
\text { (Ö.D.) }\end{array}$ & $\begin{array}{c}0.327 \\
\text { (Ö.D.) }\end{array}$ & $\begin{array}{c}0.308 \\
\text { (Ö.D.) }\end{array}$ & $\begin{array}{c}0.089 \\
\text { (Ö.D.) }\end{array}$ & - \\
\hline SÇKM & $\begin{array}{l}-0.191 \\
\text { (Ö.D.) }\end{array}$ & $\begin{array}{c}0.069 \\
\text { (Ö.D.) }\end{array}$ & $\begin{array}{l}-0.143 \\
\text { (Ö.D.) }\end{array}$ & $\begin{array}{l}-0.229 \\
\text { (Ö.D.) }\end{array}$ & $\begin{array}{l}-0.174 \\
\text { (Ö.D.) }\end{array}$ & $\begin{array}{l}-0.191 \\
\text { (Ö.D.) }\end{array}$ & $\begin{array}{l}-0.274 \\
\text { (Ö.D.) }\end{array}$ & $\begin{array}{l}-0.096 \\
\text { (Ö.D.) }\end{array}$ & $\begin{array}{c}0.369 \\
(*) \\
\end{array}$ & $\begin{array}{c}0.226 \\
\text { (Ö.D.) }\end{array}$ & $\begin{array}{c}0.141 \\
\text { (Ö.D.) }\end{array}$ & $\begin{array}{c}0.087 \\
\text { (Ö.D.) }\end{array}$ & $\begin{array}{c}0.129 \\
\text { (Ö.D.) }\end{array}$ & $\begin{array}{c}0.210 \\
\text { (Ö.D.) }\end{array}$ & $\begin{array}{c}0.000 \\
\text { (Ö.D.) }\end{array}$ & $\begin{array}{r}-0.029 \\
\text { (Ö.D.) } \\
\end{array}$ \\
\hline
\end{tabular}


Çizelge 7. Net örtü sistemi altında yapılan yetiştiricilikte parametrelere ait korelasyon analiz sonuçları.

Table 7. Results of correlation analysis belong to examined parameters in the net covering system.

\begin{tabular}{|c|c|c|c|c|c|c|c|c|c|c|c|c|c|c|c|c|}
\hline Değişkenler & BB & GÇ & GY & TYS & AYS & HSÇ & TS & PS & HA & PU & $\mathbf{P C ̧}$ & PÇA & $\mathbf{P A}$ & MEA & KK & MES \\
\hline Bitki Boyu (BB) & - & - & - & - & - & - & - & - & - & - & - & - & - & - & - & - \\
\hline Gövde Çevresi (GÇ) & $\begin{array}{c}0.344 \\
*\end{array}$ & - & - & - & - & - & - & - & - & - & - & - & - & - & - & - \\
\hline Gövde Yüksekliği (GY) & $\begin{array}{l}0.309 \\
\text { (Ö.D.) }\end{array}$ & $\begin{array}{l}0.285 \\
\text { (Ö.D.) }\end{array}$ & - & - & - & - & - & - & - & - & - & - & - & - & - & - \\
\hline Toplam Yaprak Sayısı (TYS) & $\begin{array}{c}0.204 \\
\text { (Ö.D.) }\end{array}$ & $\begin{array}{c}0.367 \\
*\end{array}$ & $\begin{array}{c}0.453 \\
* *\end{array}$ & - & - & - & - & - & - & - & - & - & - & - & - & - \\
\hline Aktif Yaprak Sayısı (AYS) & $\begin{array}{l}0.212 \\
\text { (Ö.D.) }\end{array}$ & $\begin{array}{l}0.637 \\
* * *\end{array}$ & $\begin{array}{c}0.166 \\
\text { (Ö.D.) }\end{array}$ & $\begin{array}{l}0.513 \\
* *\end{array}$ & & - & - & - & - & - & - & - & - & - & - & - \\
\hline Hevenk Sapı Çevresi (HSÇ) & $\begin{array}{c}0.470 \\
* *\end{array}$ & $\begin{array}{l}0.861 \\
* * *\end{array}$ & $\begin{array}{c}0.443 \\
* *\end{array}$ & $\begin{array}{c}0.452 \\
* *\end{array}$ & $\begin{array}{c}0.483 \\
* *\end{array}$ & - & - & - & - & - & - & - & - & - & - & - \\
\hline Tarak Sayısı (TS) & $\begin{array}{l}0.321 \\
\text { (Ö.D.) }\end{array}$ & $\begin{array}{c}0.481 \\
* *\end{array}$ & $\begin{array}{l}0.358 \\
*\end{array}$ & $\begin{array}{c}0.465 \\
* *\end{array}$ & $\begin{array}{c}0.389 \\
*\end{array}$ & $\begin{array}{c}0.561 \\
* * *\end{array}$ & - & - & - & - & - & - & - & - & - & - \\
\hline Toplam Parmak Sayısı (TPS) & $\begin{array}{l}0.115 \\
\text { (Ö.D.) }\end{array}$ & $\begin{array}{c}0.482 \\
* *\end{array}$ & $\begin{array}{c}0.432 \\
* *\end{array}$ & $\begin{array}{c}0.506 \\
* *\end{array}$ & $\begin{array}{c}0.431 \\
* *\end{array}$ & $\begin{array}{c}0.506 \\
* *\end{array}$ & $\begin{array}{l}0.687 \\
* * *\end{array}$ & - & - & - & - & - & - & - & - & - \\
\hline Hevenk Ağırlığı (HA) & $\begin{array}{l}0.021 \\
\text { (Ö.D.) }\end{array}$ & $\begin{array}{l}0.176 \\
\text { (Ö.D.) }\end{array}$ & $\begin{array}{l}0.173 \\
\text { (Ö.D.) }\end{array}$ & $\begin{array}{l}0.115 \\
\text { (Ö.D.) }\end{array}$ & $\begin{array}{l}-0.037 \\
\text { (Ö.D.) }\end{array}$ & $\begin{array}{c}0.160 \\
\text { (Ö.D.) }\end{array}$ & $\begin{array}{c}0.386 \\
*\end{array}$ & $\begin{array}{l}0.316 \\
\text { (Ö.D.) }\end{array}$ & - & - & - & - & - & - & - & - \\
\hline Parmak Uzunluğu (PU) & $\begin{array}{l}-0.023 \\
\text { (Ö.D.) }\end{array}$ & $\begin{array}{l}-0.152 \\
\text { (Ö.D.) }\end{array}$ & $\begin{array}{l}0.096 \\
\text { (Ö.D.) }\end{array}$ & $\begin{array}{l}0.090 \\
\text { (Ö.D.) }\end{array}$ & $\begin{array}{l}-0.091 \\
\text { (Ö.D.) }\end{array}$ & $\begin{array}{l}-0.074 \\
\text { (Ö.D.) }\end{array}$ & $\begin{array}{l}-0.260 \\
\text { (Ö.D.) }\end{array}$ & $\begin{array}{l}-0.258 \\
\text { (Ö.D.) }\end{array}$ & $\begin{array}{l}-0.270 \\
\text { (Ö.D.) }\end{array}$ & - & - & - & - & - & - & - \\
\hline Parmak Çevresi (PÇ) & $\begin{array}{l}0.167 \\
\text { (Ö.D.) }\end{array}$ & $\begin{array}{l}-0.100 \\
\text { (Ö.D.) }\end{array}$ & $\begin{array}{l}-0.262 \\
\text { (Ö.D.) }\end{array}$ & $\begin{array}{l}-0.261 \\
\text { (Ö.D.) }\end{array}$ & $\begin{array}{l}-0.062 \\
\text { (Ö.D.) }\end{array}$ & $\begin{array}{c}0.007 \\
\text { (Ö.D.) }\end{array}$ & $\begin{array}{l}-0.251 \\
\text { (Ö.D.) }\end{array}$ & $\begin{array}{l}-0.303 \\
\text { (Ö.D.) }\end{array}$ & $\begin{array}{c}-0.330 \\
*\end{array}$ & $\begin{array}{l}0.606 \\
* * *\end{array}$ & - & - & - & - & - & - \\
\hline Parmak Çapı (PÇA) & $\begin{array}{c}0.205 \\
\text { (Ö.D.) }\end{array}$ & $\begin{array}{l}-0.111 \\
\text { (Ö.D.) }\end{array}$ & $\begin{array}{l}-0.173 \\
\text { (Ö.D.) }\end{array}$ & $\begin{array}{l}-0.258 \\
\text { (Ö.D.) }\end{array}$ & $\begin{array}{l}-0.147 \\
\text { (Ö.D.) }\end{array}$ & $\begin{array}{l}-0.026 \\
\text { (Ö.D.) }\end{array}$ & $\begin{array}{l}-0.135 \\
\text { (Ö.D.) }\end{array}$ & $\begin{array}{l}-0.136 \\
\text { (Ö.D.) }\end{array}$ & $\begin{array}{l}-0.184 \\
\text { (Ö.D.) }\end{array}$ & $\begin{array}{c}0.553 \\
* * *\end{array}$ & $\begin{array}{c}0.805 \\
* * *\end{array}$ & - & - & - & - & - \\
\hline Parmak Ağırlı̆̆ (PA) & $\begin{array}{c}0.177 \\
\text { (Ö.D.) }\end{array}$ & $\begin{array}{l}-0.089 \\
\text { (Ö.D.) }\end{array}$ & $\begin{array}{c}0.014 \\
\text { (Ö.D.) }\end{array}$ & $\begin{array}{l}-0.003 \\
\text { (Ö.D.) }\end{array}$ & $\begin{array}{l}-0.062 \\
\text { (Ö.D.) }\end{array}$ & $\begin{array}{c}0.027 \\
\text { (Ö.D.) }\end{array}$ & $\begin{array}{l}-0.271 \\
\text { (Ö.D.) }\end{array}$ & $\begin{array}{l}-0.211 \\
\text { (Ö.D.) }\end{array}$ & $\begin{array}{l}-0.314 \\
\text { (Ö.D.) }\end{array}$ & $\begin{array}{c}0.853 \\
* * *\end{array}$ & $\begin{array}{c}0.802 \\
* * *\end{array}$ & $\begin{array}{c}0.811 \\
* * *\end{array}$ & - & - & - & - \\
\hline Meyve Eti Ağırlığı (MEA) & $\begin{array}{c}0.089 \\
\text { (Ö.D.) }\end{array}$ & $\begin{array}{l}-0.274 \\
\text { (Ö.D.) }\end{array}$ & $\begin{array}{c}-0.010 \\
\text { (Ö.D.) }\end{array}$ & $\begin{array}{c}0.134 \\
\text { (Ö.D.) }\end{array}$ & $\begin{array}{l}-0.139 \\
\text { (Ö.D.) }\end{array}$ & $\begin{array}{l}-0.180 \\
\text { (Ö.D.) }\end{array}$ & $\begin{array}{l}-0.273 \\
\text { (Ö.D.) }\end{array}$ & $\begin{array}{c}0.032 \\
\text { (Ö.D.) }\end{array}$ & $\begin{array}{l}-0.188 \\
\text { (Ö.D.) }\end{array}$ & $\begin{array}{c}0.572 \\
* * *\end{array}$ & $\begin{array}{c}0.471 \\
* *\end{array}$ & $\begin{array}{c}0.592 \\
* * *\end{array}$ & $\begin{array}{c}0.731 \\
* * *\end{array}$ & - & - & - \\
\hline Kabuk Kalınlığı (KK) & $\begin{array}{l}-0.132 \\
\text { (Ö.D.) }\end{array}$ & $\begin{array}{l}-0.247 \\
\text { (Ö.D.) }\end{array}$ & $\begin{array}{l}-0.150 \\
\text { (Ö.D.) }\end{array}$ & $\begin{array}{c}0.265 \\
\text { (Ö.D.) }\end{array}$ & $\begin{array}{l}-0.059 \\
\text { (Ö.D.) }\end{array}$ & $\begin{array}{l}-0.178 \\
\text { (Ö.D.) }\end{array}$ & $\begin{array}{l}-0.267 \\
\text { (Ö.D.) }\end{array}$ & $\begin{array}{l}-0.120 \\
\text { (Ö.D.) }\end{array}$ & $\begin{array}{c}0.050 \\
\text { (Ö.D.) }\end{array}$ & $\begin{array}{c}0.109 \\
\text { (Ö.D.) }\end{array}$ & $\begin{array}{c}0.009 \\
\text { (Ö.D.) }\end{array}$ & $\begin{array}{l}-0.053 \\
\text { (Ö.D.) }\end{array}$ & $\begin{array}{c}0.104 \\
\text { (Ö.D.) }\end{array}$ & $\begin{array}{c}0.282 \\
\text { (Ö.D.) }\end{array}$ & - & - \\
\hline Meyve Eti Sertliği (MES) & $\begin{array}{l}-0.018 \\
\text { (Ö.D.) }\end{array}$ & $\begin{array}{l}-0.236 \\
\text { (Ö.D.) }\end{array}$ & $\begin{array}{l}0.300 \\
\text { (Ö.D.) }\end{array}$ & $\begin{array}{l}0.215 \\
\text { (Ö.D.) }\end{array}$ & $\begin{array}{l}-0.326 \\
\text { (Ö.D.) }\end{array}$ & $\begin{array}{l}-0.129 \\
\text { (Ö.D.) }\end{array}$ & $\begin{array}{c}0.071 \\
\text { (Ö.D.) }\end{array}$ & $\begin{array}{l}0.198 \\
\text { (Ö.D.) }\end{array}$ & $\begin{array}{c}0.346 \\
*\end{array}$ & $\begin{array}{l}0.173 \\
\text { (Ö.D.) }\end{array}$ & $\begin{array}{l}-0.130 \\
\text { (Ö.D.) }\end{array}$ & $\begin{array}{c}0.083 \\
\text { (Ö.D.) }\end{array}$ & $\begin{array}{c}0.124 \\
\text { (Ö.D.) }\end{array}$ & $\begin{array}{c}0.320 \\
\text { (Ö.D.) }\end{array}$ & $\begin{array}{l}-0.050 \\
\text { (Ö.D.) }\end{array}$ & - \\
\hline SÇKM & $\begin{array}{c}0.012 \\
\text { (Ö.D.) }\end{array}$ & $\begin{array}{l}-0.036 \\
\text { (Ö.D.) }\end{array}$ & $\begin{array}{l}-0.214 \\
\text { (Ö.D.) }\end{array}$ & $\begin{array}{l}-0.153 \\
\text { (Ö.D.) }\end{array}$ & $\begin{array}{c}0.059 \\
\text { (Ö.D.) }\end{array}$ & $\begin{array}{c}0.006 \\
\text { (Ö.D.) }\end{array}$ & $\begin{array}{l}-0.227 \\
\text { (Ö.D.) }\end{array}$ & $\begin{array}{l}-0.138 \\
\text { (Ö.D.) }\end{array}$ & $\begin{array}{l}-0.216 \\
\text { (Ö.D.) }\end{array}$ & $\begin{array}{c}0.027 \\
\text { (Ö.D.) }\end{array}$ & $\begin{array}{c}0.333 \\
* \\
\end{array}$ & $\begin{array}{c}0.165 \\
\text { (Ö.D.) }\end{array}$ & $\begin{array}{c}0.092 \\
\text { (Ö.D.) }\end{array}$ & $\begin{array}{l}-0.028 \\
\text { (Ö.D.) }\end{array}$ & $\begin{array}{c}0.078 \\
\text { (Ö.D.) }\end{array}$ & $\begin{array}{r}-0.227 \\
\text { (Ö.D.) } \\
\end{array}$ \\
\hline
\end{tabular}




\section{Teşekkür}

$\mathrm{Bu}$ araştırma, Akdeniz Üniversitesi Bilimsel Araştırma Projeleri Koordinasyon Birimi tarafından desteklenmiştir. Makalenin istatistikleri, İstatistik Danışmanlık Uygulama ve Araştırma Merkezi (AKIDUAM) tarafından yapılmıştır. Yazarlar, her iki birime desteklerinden dolayı teşekkürü bir borç bilir.

\section{Kaynaklar}

Altınkaya L (2016) Net örtü sistemi altında muz yetiştirme olanakları. Yüksek Lisans Tezi, Akdeniz Üniversitesi Fen Bilimleri Enstitüsü, Antalya.

Balkıç R, Gübbük H, Altınkaya L (2017) Muz hevenklerinde farklı tip ve renkte koruyucu torba uygulamalarının verim ve kalite üzerine etkileri. Adnan Menderes Üniversitesi Ziraat Fakültesi Dergisi 14(1): 29-33.

Eckstein K, Fraser C, Husselmann J, Murray NT (1998a) The evaluation of promising new banana cultivars. Acta Horticulturae 490: 57-70.

Eckstein K, Fraser C, Joubert W (1998b) Greenhouse cultivation of bananas in South Africa. I. Internation Greenhoual Symposium on Banana in the Subtropics. Acta Horticulturae 490: 135-146.

Fao (2017) Statistical database. http://www.fao.org/faostat/en/\#data/QC. Accessed 29 August 2019.

Galan Sauco V, Cabrera Cabrera J, Hernandez Delgado PM, Rodriguez Pastor MC (1998) Comparison of protected and open-air cultivation of Grande Naine and Dwarf Cavendish bananas. Acta Horticulturae 490: 247-259.

Galan Sauco V (2002) Greenhouse cultivation of tropical fruits. Proc. IS on Trop. \& Subtrop. Fruits, Ed. R. Drew, Acta Horticulturae 575: 727-735.

Galan Sauco V, Rogriguez Pastor MAC (2007) Greenhouse cultivation of papaya. Acta Horticulturae 740: 191-195.

Gubbuk H, Pekmezci M (2004) Comparison of open-field and protected cultivation of banana (Musa spp. AAA) in the coastal area of Turkey. New Zealand Journal of Crop and Horticultural Science 32: 375-378.

Gubbuk H, Pekmezci M, Erkan M (2004) Production potential of Cavendish cultivars (Musa spp. AAA) under greenhouse and field conditions in subtropical areas of Turkey. Acta Agriculturae Scandinavica, Section B- Plant Soil Science 54(4): 249-253.
Gübbük H, Pekmezci M, Selli S, Erkan M, Kafkas E, Pinar H, Güven D, Güneş E (2010) Değişik lokasyonlarda açıkta ve örtüaltında yetiștirilen 'Dwarf Cavendish' muz çeșidinde verim, bazı kalite kriterleri ve aroma maddeleri ile meyvelerin derim sonras özelliklerinin belirlenmesi üzerinde araștırmalar. TÜBİTAK, Proje No: 107O156. s. 247.

Haijun L, Cohen S, Lemcoff JH, Israeli Y, Tanny J (2015) Sap flow, canopy conductance and microclimate in a banana screenhouse. Agricultural and Forest Meteorology 201: 165-175

Kader AA (2002) Postharvest technology of horticultural crop. $3^{\text {rd }}$ Edition, Publication 3311. Division of Agriculture and Natural Resources, University of California, Oakland, California, USA.

Martelleto LAP, Riberio R DE LD, Sudo-Martelleto M, Vasconcellos MA DA S, Marin SLD, Pereira MB (2008) Cycle development and agronomic performance of organic papaya cultivation in protected environment. Revista Brasileira De Fruticultura 30(3): 662-666.

McGuire RG (1992) Reporting of objective color measurements. HortScience 27: 1254-1255.

Mendez Hernandez C (1998) A comparison of the parent crop of three cultivars of banana in the open air and under plastic mesh in the North of Tenerife. Acta Horticulturae 490: 97-101.

Pirkner M, Tanny J, Shapira O, Teitel M, Cohen S, Shahak Y, Israeli Y (2014) The effect of screen type on crop micro-climate, reference evapotranspiration and yield of a screenhouse banana plantation. Scientia Horticulturae 180: 32-39.

Refaie KM, Esmail AAM, Medany MA (2012) The Respone of banana production and fruit quality to shading nets. Journal of Applied Sciences Research 8(12): 5758-5764.

Siqueira MB, Katul GG, Tanny J (2012) The effect of the screen on the mass, momentum, and energy exchange rates of a uniform crop situated in an extensive screenhouse. Bound-Layer Meteorol 142(3): 339-363.

Stover RH, Simmonds NW (1987) Bananas. $3^{\text {rd }}$ Edition, Harlow, Longman. Scientific and Technical, Harlow, UK, pp. 468.

Tanny J, Lukyanov V, Neiman M, Cohen S, Teitel M, Seginer I (2018) Energy balance and partitioning and vertical profiles of turbulence characteristics during initial growth of a banana plantation in a screenhouse. Agricultural and Forest Meteorology 256-257: 53-60.

Teitel M, Liang H, Tanny J, Garcia-Teruel M, Levi A, Ibanez PF, Alon $\mathrm{H}$ (2017) Effect of roof height on microclimate and plant characteristics in an insect-proof screenhouse with impermeable sidewalls. Biosystems Engineering 162: 11-19. 